\title{
Self-Paced E-Training in E-Learning for University Teaching Staff
}

\author{
http://dx.doi.org/10.3991/ijac.v8i1.4371 \\ Norah Al-Malki, Miada Almasre, Abdullah Al-Malki, and Rania Al-Harbi \\ King Abdulaziz University, Jeddah, Saudi Arabia
}

\begin{abstract}
The shift towards adopting e-training methods and practices in the workplace to equip staff with soft and hard skills have become an essential component of training in many Higher Education institutions. The aim of this paper is to advocate such a shift in Saudi universities through presenting the preliminary outcomes of a shortscale pilot study conducted by the Deanship of E-learning and Distance Education (DELDE) during August 2014. Basically, the paper introduces the results of a first run of a self-paced e-training program focusing on introducing topics related to e-learning development and instruction. The paper 1) explores the pedagogical motivation for adopting the self-paced learning model, 2) outlines the elements of the developed course, and 3 ) discusses the results of the first run of the e-training program.
\end{abstract}

Index Terms-e-learning, e-training, self-paced learning, university staff training

\section{INTRODUCTION}

E-training (or web-based training) has become an innovative way of training in Higher Education (HE) institutions all over the world due to the rapid growth in information technology infrastructure and the excessive demand for cost-effective ways to deliver training to staff.

The transition from face-to-face instructional models to online learning is a complex one requiring specialized training in delivering quality educational experiences to the learners. HE institutions started to take an interest in fostering a desire for knowledge acquisition in its teaching staff, and offering training opportunities that fulfill their needs as well as suit their busy schedules. In this context, where professional development is highly required but inconveniently obstructed by workload demands, etraining comes into the picture as a solution which universities can invest in to support the self-development aspirations of its teaching staff.

Rhode [1], for instance, reports the adoption and relative success of such an initiative in the Northern Illinois University, where a self-paced e-training program was designed as a certificate requirement for those teaching staff intending to teach online. See and Teetor $\lceil 2\rceil$ investigated the outcome of a similar project in Arizona University, which targeted library officials in the university. They reported how the e-training program was successful in providing "a ubiquitous, point-of-need virtual learning environment that successfully prepared them to staff a 24/7 research library". Gold's [31 study employs a constructivist approach to e-training which, as the researcher concludes, influenced the way teachers started to think of online learning as an extension of their educational duties.
Because the present researchers are with the view that "individual e-learners have a positive attitude to this approach to learning" [4], they decided to pilot migration of training to an online environment (Blackboard LMS) in an attempt to advocate e-training at King Abdulaziz University (KAU) for teaching staff who need access to resources on how to design and deliver their courses in an online environment.

Consequently, this paper presents the outcomes of a short-scale experiment conducted during August 2014, when a group of teaching staff (28) were enrolled for a two-week, first run of a self-paced e-training program designed in the Deanship of E-learning and Distance Education (DELDE) and delivered via the Blackboard LMS, with the aim of introducing concepts related to online learning development and instruction. The paper will focus on presenting the researchers' pedagogical rationale for adopting self-paced learning, the components of the developed course, and the results of the first run of the etraining program.

\section{A. DELDE's Shift towards E-training}

DELDE has recognised the importance of designing high quality training programs for KAU staff, who want to effect a transformation towards e-learning. Its state-of-theart onsite training program targets the realization of the following objectives: 1) spreading the awareness of elearning models and practices, 2) effecting a shift towards more learner-cantered pedagogies in the context of online learning, 3) maximizing the potential of online learning solutions adopted by KAU through ensuring that staff is well-trained on how to use them. To that end, DELDE created a comprehensive training program that considers both pedagogical and technical competences which the teaching staff must acquire prior to teaching online.

What the researchers noticed was that face-to-face training has not been adequate for several reasons, which are outlined below:

1. As with all learners, the enrolled trainees have different learning styles. The training program had to offer multimodal resources (video, audio, text, etc.) so that trainees' needs be met adequately and successfully. Although lasting up to 4 hours per session, face-toface sessions did not provide the opportunity for introducing multimodal content.

2. The training was not contextualized; i.e. both pedagogical and technical competences were delivered in disassociation from the environment in which these skills had to be mastered. This is not to say that trainees were not exposed to proper application in either field, but that the training content or applications 
were not part of a complete package delivered via the online environment under exploration, which should have been the case, as the researchers argue. What better way to train staff on using forums in their courses, than requiring them to participate in ones which are created for illustrating the pedagogical as well as the technical aspects related to using forums in online learning?

\section{B. Development of the E-training Program}

The researchers, confronted with the task of program development, had to consider a set of national standards outlined by the Saudi National Commission for Assessment and Academic Accreditation (NCAAA) in the hope of maintaining quality while addressing trainees' immediate needs, and due to the fact that this training program was conducted online, the Academic and Technical standards set by the Saudi National Center for E-Learning and Distance Learning (NCeL) were consulted as well.

All in all, these standards agreed on the necessity of developing programs/courses that 1) are based on welldefined pedagogical models, 2) support learners' collaboration, interaction, and engagement, as well as 3 ) provide timely and accurate assessments and feedback.

After setting out these quality specifications, the researchers, aided by instructional designers in DELDE, commenced the design process of an online training program offered to KAU faculty who would be interested in gaining more experience in the principles and practices of online instruction.

The choice of the self-paced model was based primarily on trainees' needs. They could not attend onsite straining, but at the same time-- and because of their teaching schedules-- they could not enroll in live e-training. Also, they needed more time to explore theoretical concepts which they have not been exposed to, and which onsite training or live e-training cannot adequately present due to time restrictions.

Barrow $\lceil 5\rceil$ defines self-paced training as "training which is taken at a time and a pace determined by the user; often used for text or audio/video self-study courses". Because the researchers were aware of the limitations of self-paced learning, including for example the absence of learner motivation, they decided to include interactive assessments, and require the online presence of the trainers to support trainees learning practices and encourage them to complete the course.

It is envisioned that prospective trainees who enroll in this program should acquire intermediate-to-advanced levels of familiarity with the requirements of teaching online through accomplishing a structured set of highly interactive and engaging activities that will expose them to various instructional strategies for successful teaching using the Blackboard LMS.

The program modules, collectively referred to as, "ELearning Training" are structured as a self-paced online course that is based on the training kit developed by DELDE. The Modules are listed below:

1. Module One: Instructional Design

2. Module Two: Online Instruction

3. Module Three: The Blackboard LMS: How To

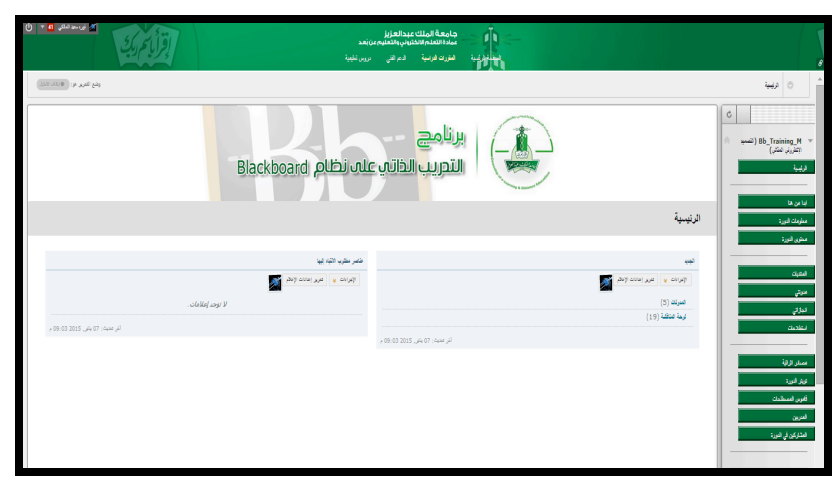

Figure 1. E-training home page

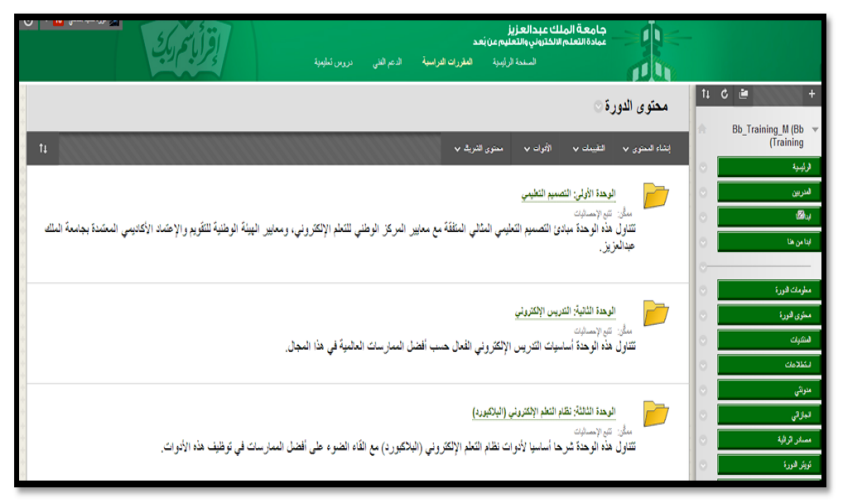

Figure 2. E-training modules' page

Fig. 1 and Fig. 2 show the e-training home page and the Modules' page in the course, where content is organized into folders.

To ensure best practice and course quality, the following components and development techniques were taken into account:

a. A learner-style survey was set up, so the trainers can adapt their pedagogical and technical support to trainees' needs.

b. A structured approach to organizing course content in folders was adopted to ensure ease of access and coherency of overall course structure. Folders' content (presentations, videos, pdfs, web links, assessments, and individual or collaborative activities) included ample descriptions and guides for trainees on how to use them and their purpose.

c. A "Strat Here" page was set up to explain the pedagogical model used (self-paced learning with assessments), and a virtual tour of the course, so trainers will not feel lost.

d. A "Course Information" page was set up as well with a Course Description, Objectives, Syllabus, Assessment and Grading chart.

The researchers believe that the best way to obtain meaningful results for the e-training is though designing more effective assessments [6]. Therefore, they enhanced each learning module with the following types of assessments to encourage trainees apply the knowledge they have learned:

a. Discussion Forums: trainees were required to post regularly in the course's forums on topics explored in each module. The objective was twofold: 1) to ensure that they can express their understand- 
ing of the e-learning concepts being presented, and 2) get more practice with the tool and how to use it in a sound pedagogical context.

b. Individual Blogs: for reflective writing on what they have been studying.

c. Tests: short quizzes to measure their acquisition of basic knowledge-related competences.

d. Self-assessment surveys: which were included in the modules to help the trainees reflect on principles and soft skills related to teaching, in general, and e-learning, in particular.

e. An assignment Task: they were required to create a learning object following the principles discussed in the course.

The researchers included a gamified assessment element using the Blackboard Achievement tool, whereby if a trainee completed the activities assigned in Module One, for example, she gets a Badge entitled "The Exemplary Instructional Designer". These badges and certificates are sharable on social media and the web generally and considered motivational in e-learning contexts. The trainee's Achievement page shows all the Badges she gets as shown in Fig. 3.

\section{METHODS}

\section{A. Data Collection}

The preliminary data collected for the paper during this stage of the project comes from three Blackboard Usage Reports (all user activity report, forum activity report, and overall course activity report), which present quantitative figures of trainees' interaction with the course. In addition, an end-of-the-course survey was administered to gather data on trainees' reaction to course content and delivery methods.

\section{B. Participants}

28 teaching staff were enrolled in the course's pilot, and were asked to review course content, engage in forum discussions, suggest appropriate modifications, and attempt some of the activities listed in the course. The staff came with an intermediate-to-advanced levels of ICT knowledge of how to use web tools like forums, blogs, eexams, etc. Some of them had already received training on using the Blackboard LMS and others did not.

\section{FINDINGS AND DISCUSSION}

The collected data indicated a moderately positive view of the e-training program as specified below:

\section{A. The Blackboard Reports}

The "All User Activity Report" (Table I) demonstrates the trainees' interest in Content Area Items where the multimodal content folders are stored for easy review, and the Discussion Forums where course interaction is taking place. But, we have to note that these percentages indicate review status of the listed items not necessarily the trainees' participation in them. We used this report, nonetheless, to demonstrate that a self-paced program's strongest asset should be its content and interaction.

The "Forum Activity Report" (Table II) illustrates the trainees' engagement with the course forums. Again, as with the previous report, it is the review status that is be-

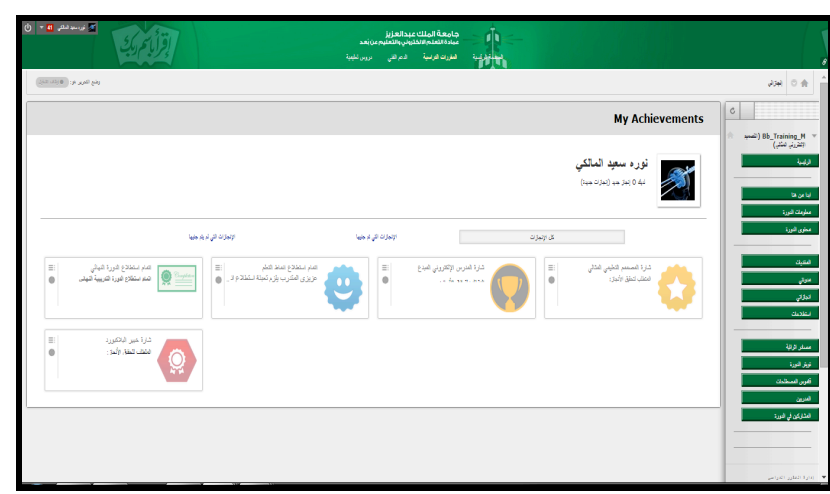

Figure 3. Achievement page

TABLE I. ALL USER ACTIVITY REPORT

\begin{tabular}{|l|c|}
\hline \multicolumn{1}{|c|}{ Tool } & Percentage \\
\hline Announcements & $0.81 \%$ \\
\hline Course Files & $0.10 \%$ \\
\hline Blogs & $2.47 \%$ \\
\hline Content item & $77.30 \%$ \\
\hline Email & $0.23 \%$ \\
\hline Users & $3.07 \%$ \\
\hline Discussion Boards & $13.12 \%$ \\
\hline Groups & $0.57 \%$ \\
\hline Grade Center & $1.69 \%$ \\
\hline Course Messages & $0.13 \%$ \\
\hline Contact & $0.05 \%$ \\
\hline My Grades & $0.36 \%$ \\
\hline Tasks & $0.03 \%$ \\
\hline
\end{tabular}

TABLE II. FORUM ACTIVITY REPORT

\begin{tabular}{|l|c|}
\hline \multicolumn{1}{|c|}{ Forum } & Percentage \\
\hline Training Project Group forum & $0.00 \%$ \\
\hline Internal Group forum & $0.00 \%$ \\
\hline FAQ Forum & $27.12 \%$ \\
\hline Suggestions Forum & $5.08 \%$ \\
\hline Module One Forum & $7.63 \%$ \\
\hline Module Two Forum & $2.54 \%$ \\
\hline Module Three Forum & $4.24 \%$ \\
\hline Join for A Cuppa Forum & $53.39 \%$ \\
\hline
\end{tabular}

ing measured. The level of actual engagement with interaction via the forums will be pursued in further studies.

Fig. 4 shows the results of the "Overall Course Activity Report", which was run for only one-week period during which the course was tested by users and reviewed by trainees. The aim was to investigate how much time was spent on a daily basis by the trainees in reviewing the materials and participating in the interaction. The highest percentage was during the fourth day, when the collective hours spent by trainees online exceeded the 20-hours mark.

The researchers want to emphasize that this first run of the e-training program was directed more towards making sure that DELDE can measure the effectiveness of training than a real application of the program. If, as these reports indicate, program coordinators can extract such detailed reports about the user experience and usage, then what is left to guarantee the success of such an e-training endeavour is to administer an end-of-course survey which inquires about specific aspects of e-training. 


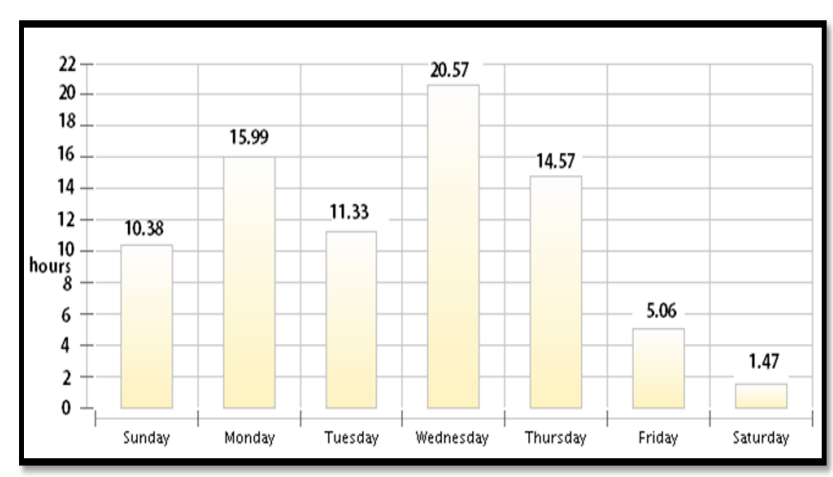

Figure 4. Overall all activity report

TABLE III. RESULTS OF END-OF-COURSE SURVEY

\begin{tabular}{|l|c|c|c|}
\hline \multicolumn{1}{|c|}{ Item } & Agree & $\begin{array}{c}\text { Neither Agree } \\
\text { nor disagree }\end{array}$ & Disagree \\
\hline $\begin{array}{l}\text { Module Objectives were } \\
\text { stated for each module }\end{array}$ & $100 \%$ & $0 \%$ & $0 \%$ \\
\hline $\begin{array}{l}\text { Course Structure was } \\
\text { clear }\end{array}$ & $70 \%$ & $0 \%$ & $30 \%$ \\
\hline $\begin{array}{l}\text { Module Structure was } \\
\text { logical }\end{array}$ & $66.6 \%$ & $16.6 \%$ & $16.6 \%$ \\
\hline $\begin{array}{l}\text { The topics presented } \\
\text { added to my knowledge } \\
\text { about e-learning }\end{array}$ & $66.6 \%$ & $33.3 \%$ & $0 \%$ \\
\hline $\begin{array}{l}\text { The topics presented in } \\
\text { the course were engaging }\end{array}$ & $50 \%$ & $33.3 \%$ & $16.66 \%$ \\
\hline $\begin{array}{l}\text { The topics presented in } \\
\text { the course are very } \\
\text { important for those } \\
\text { involved with e-learning }\end{array}$ & $100 \%$ & $0 \%$ & $0 \%$ \\
\hline $\begin{array}{l}\text { Assessments were suita- } \\
\text { ble for me }\end{array}$ & $88 \%$ & $10 \%$ & $2 \%$ \\
\hline $\begin{array}{l}\text { The multimedia used was } \\
\text { related to course content }\end{array}$ & $83.333 \%$ & $16.6 \%$ & $0 \%$ \\
\hline $\begin{array}{l}\text { The interactive strategies } \\
\text { and tools were clearly } \\
\text { indicated in the course }\end{array}$ & $66.667 \%$ & $33.33 \%$ & $0 \%$ \\
\hline $\begin{array}{l}\text { Course resources were } \\
\text { useful }\end{array}$ & $84 \%$ & $5 \%$ & $11 \%$ \\
\hline $\begin{array}{l}\text { Interaction with trainers } \\
\text { was easy }\end{array}$ & $100 \%$ & $0 \%$ & $0 \%$ \\
\hline
\end{tabular}

The results of the end-of-course survey indicated, as table III shows, a relatively positive evaluation of the course, however, with much to be said about presentation and quality specifics that have to be given priority in future re-runs of the e-training program. The survey items consisted of 11 Likert-scale questions inquiring about course organization, content structure, content meaningfulness in the context of e-learning, multimodality features, suitability of assessments, and availability of support. $100 \%$ of trainees agreed that the modules' objectives were clear, their topics were important, and the content multimodal. $100 \%$ of the trainees believed that interaction with trainers was facilitated. Assessments, and course resource page received favourable rating as well $(88 \%$ and $84 \%$ respectively).

\section{CONCLUSION}

E-training in HE institutions is surely an investment that has to be maximized. DELDE's engagement with etraining for KAU staff is still experiential and needs testing before embarking on administering large-scale training programs. The Blackboard LMS with its potential of interactivity and collaboration tools offers us a chance to rethink our training models and try online training, at least as a blend with face-to-face training. This will allow DELDE to transition from providing onsite and expensive training to a more dynamic and self-paced from of training.

\section{REFERENCES}

[1] J. Rhode. "Designing self-paced training modules as the foundation of online faculty certification," Paper published in the proceedings of the 19th Annual Sloan Consortium International Conference on Online Learning, Orlando, FL. 2013.

[2] Andrew See and Travis Stephen Teetor. "Effective e-training: using a course management system and e-learning tools to train library employees," Journal of Access Services, Vol. 11:2, pp. 6690, 2014. http://dx.doi.org/10.1080/15367967.2014.896217

[3] Sanford Gold. "A constructivist approach to online training for online teachers," JALN, Vol. 5 (1), pp. 35-57, May 2001.

[4] B. Allan and D. Lewis. "Virtual learning communities as a vehicle for workforce development: A case study," Journal of Workplace Learning, Vol. 18(6), pp. 367-383. 2006. http://dx.doi.org/10.1108/13665620610682099

[5] Collin Barrow. E-Training and Development: Training and Development 11.3. John Wiley \& Sons, 2003. pp.9.

[6] M. Driscoll. "Building better e-assessments," ASTD Learning Circuits. July 2001. [Online] Available at: www.learning circuits.org.

\section{AUTHORS}

Norah Al-Malki is with Department of European Languages in King Abdulaziz University, Jeddah, Kingdom of Saudi Arabia (e-mail: naalmalki1@kau.edu.sa).

Miada Almasre is with Deanship of E-Learning and Distance Education in King Abdulaziz University, Jeddah, Kingdom of Saudi Arabia (e-mail: malmasre@kau.edu.sa).

Abdullah Al-Malki is with Deanship of E-Learning and Distance Education in King Abdulaziz University, Jeddah, Kingdom of Saudi Arabia (e-mail: asalmalki@kau.edu.sa).

Rania Al-Harbi is with Deanship of E-Learning and Distance Education in King Abdulaziz University, Jeddah, Kingdom of Saudi Arabia (e-mail: rallehabi@kau.edu.sa).

Submitted 07 January 2015. Published as submitted by the authors 10 March 2015. 